\title{
The Study on the factors and Countermeasures of knowledge-based workers' loyalty in state-owned Commercial Banks
}

\author{
- based on the Psychological contract theory
}

\author{
Liwei Wang \\ International Business School \\ Yunnan University of Finance and Economics \\ Kunming, China \\ 1273553993@qq.com \\ Ying Yang* \\ International Business School
}

\author{
Yunnan University of Finance and Economics \\ Kunming, China \\ 11476423@qq.com \\ Yiting Luo \\ International Business School \\ Yunnan University of Finance and Economics \\ Kunming, China \\ 372402411@qq.com
}

\begin{abstract}
OBOR (One Belt And One Road), the transformation of China's banking industry speeds up the pace, but during the transition, bank neglects the talent management, resulting in serious brain drain phenomenon. Therefore, in this paper, we analyzed the characteristics of knowledge-based employee, based on the formation process of knowledge-based employee's psychological contract, analyzing the psychological contract violation to impact the development of knowledge-based employee in State-owned Commercial Bank (SOCB). Through the improvement of salary system, the adjustment of performance evaluation mechanism, the establishment of good personnel management mechanism, the perfection of personal career planning to improve the loyalty of employees, then to cope with the impact of the external environment.
\end{abstract}

Keywords-State-owned Commercial Bank (SOCB); knowledge-based employee; loyalty index; psychological contract; suggestion

\section{INTRODUCTION}

\section{A. Research Background}

Decline in profit margin, credit risk exposure, nonperforming loan ratio rose.......under the background of China's economic downward pressure, the bank ushered in a difficult period. In the recent years, China's economic and financial situation emerges a new trend, in this new situation, the challenges that the bank downturn and structural adjustment, financial disintermediation, technology development and the emerging financial industry cause the turnover number of knowledge-based employee expands continually [1]. So the article based on the psychological contract theory to study the influence factors of knowledgebased employee's loyalty, then put forward related suggestions.

\section{B. The concept and characteristics of knowledge-based employee in $S O C B$}

1) The concept of knowledge-based employee in SOCB

Peter Deruk put forward the concept of knowledge workers in the $50 \mathrm{~s}$ of last century, that is, those who master and use symbols and concepts, use knowledge or information to work. With the change of the times, many scholars conform to the development of the times, and give a more detailed overview of the knowledge workers. Therefore, combined with the current development needs of the banking industry, that knowledge-based employee of SOCB means to have a good educational background and learning experience, grasp the rich financial, economic and management knowledge, have a strong learning desire and ability to innovate, to use modern financial means to improve work efficiency, job creation value brainworkers [3].

2) The characteristics of knowledge-based employee in $S O C B$

As an industry with higher professional requirements, the knowledge-based employee has the following characteristics: first, strongly professional, to master relevant knowledge and skills of finance, strong learning ability and high personal comprehensive quality; Second is the high level of personal pursuit, they not just satisfied with material needs, but also pay attention to the realization of self-worth, eager to recognize for inner satisfaction of the organization; Third is high flow rate, due to the industry of knowledge staff is in a state of demand is less than supply, so the knowledge staffs with rich work experience, customer resources is undoubtedly the object that banks rushed to pursuit. Therefore, when the organization can't meet their own needs, knowledge workers tend to choose a better way to achieve their own value. 


\section{3) The meaning of loyalty}

With the characteristics of individuation, innovation and independence of knowledge workers, loyalty can be interpreted from two perspectives: behavior loyalty and attitude loyalty. Behavioral loyalty is the premise of attitude loyalty, and it is the lower level of loyalty; Attitude loyalty is the deepening and extension of behavioral loyalty, which is a higher level of loyalty. Behavioral loyalty in the performance of serious work, the command of the absolute obedience to superiors, but in this case, the staff may be subject to remuneration, rank and other material conditions. Attitude loyalty are embodied in the high recognition of enterprise culture, and continue to use their intellectual capital to create value for the enterprise, and produce certain emotional attachment to the enterprise, reflects the tendency of employee service. One is the behavior of organizational support, one is the ideological organizational identity, both in the same body is always exist at the same time, complement each other.

\section{RESEARCH ON PSYCHOLOGICAL CONTRACT}

\section{A. The concept of psychological contract}

The psychological contract is formally put forward by Sean, a famous American management psychologist. In his view, the psychological contract is an individual will be dedicated to the organization and desire to get between, as well as the organization will be based on individual expectations of the harvest and provide a cooperation. Although this is not a tangible contract, it plays the role of tangible contract. Enterprises should clearly understand the needs and aspirations of each employee, and satisfy as much as possible; The Staff is also dedicated to the development of enterprises, because they believe that companies can meet their needs and aspirations. It can be described as a state, in which the development of the enterprise growth and employee didn't pass a paper contract, but their "focus" of enterprises and employees is still able to find a decision, as a contract to regulate.

\section{B. The mechanism of psychological contract violation}

In order to adapt to the current fierce competition and the changing external environment, most organizations have to change the existing management model, personnel structure and employment relationship, which will increase the possibility of psychological contract violation. After the perception of contract breach, by the individual differences, the impact of organizational practice, employees will make four responses: turnover, lower job performance (perform duties within the formal job), reduce outside the job performance (such as overtime, to help colleagues), antisocial behavior (such as combat, revenge, theft) [2].

At present, the psychological contract is the starting point of the academic field, the research on the incentive factors of the knowledge workers in SOCB that based on psychological contract violation is extensive, but rarely on the relationship between psychological contract and employee loyalty were discussed: more employee psychological contract finished, higher employee loyalty. The development of SOCB cannot do without the knowledge-based employee, the loss of knowledge workers will bring non-negligible effect to organization's development. So this article according to the specific situation combining psychological contract and employee loyalty, analyze the factors that affect employee loyalty's decline, and puts forward related suggestions.

\section{THE INFLUENCING FACTORS OF KNOWLEDGE-BASED EMPLOYEE IN SOCB}

According to the survey, by the end of 2016, China's four major state-owned commercial banks accumulated 35 thousand jobs, Chinese bank employs 3.8 million people, although the number of layoffs accounted for less than $1 \%$, far lower than the natural turnover rate, this reflects the current China banking is undergoing tremendous changes. Bank as an intelligence intensive industry, the demand for higher professional talents is larger, and the loss of knowledge workers is a huge loss for banks. Combined with the realistic background, it is not difficult to see that the state-owned commercial banks are facing unprecedented challenges. Therefore, it is an urgent need to solve the problem of improving employee loyalty and retaining talents.

\section{A. The relationship between psychological contract and loyalty}

Knowledge workers of SOCB have a high level of education, in addition to a certain material needs, there is a higher level of demand. Therefore, when employees work in earnest, after fulfill the obligation for the organization, expect organization to fulfill their commitments, such as reasonable salary, reasonable post allocation, fair performance appraisal results, fair promotion result etc. By contrast, when an employee's inner expectations are violated, loyalty decreases.

The psychological contract is inseparable from employee loyalty. Psychological contract violation to the knowledge staff's loyalty will produce a negative effect: when the knowledge workers' psychological contract has destroyed, could lead to knowledge workers distrust organization, to pay more attention to personal interests, to redefine the relationship of psychological contract and even turnover, makes the loyalty decline. Combined with the actual situation, the factors that influence the knowledge-based employee loyalty are: the impact of the emerging financial formats, the impact of the development of science and technology, the impact of the development of science and technology, and the personal career plan. These four factors are negatively correlated with employee loyalty, the greater the impact, the more obvious shortcomings, the greater the need for personal self-worth, the lower employee loyalty to the organization. From the perspective of psychological contract to analyze the cause of the loyalty, the internal demand for deeper understanding of the staff, suit the remedy to the case" to arouse the enthusiasm of the staff, improve staff loyalty to the organization, the organization can develop.

\section{B. Factors leading to psychological contract violation}

\section{1) The impact of emerging financial formats}

Emerging financial formats, namely Internet companies are widely involved in the financial industry form, with "Internet plus financial" for the characteristics of the Internet financial industry. The rise of emerging financial markets has 
been a magnet for bankers. Internet banking as a new format, so the greater demand for knowledge workers, through higher salaries to attract more talent. According to statistics, at present the new employees in financial industry starting salary is the annual salary of 100 thousand Yuan, with 2 3 years work experience can achieve the basic $50 \%$ in income growth, the income level of key employees in the 25 35 million and the supervisor at around 450 thousand. Many employees reflect that emerging industry not only meet their pursuit of material, also provides new development opportunities for them and different working experience for them, improve working enthusiasm, create more achievements than before. The "golden rice bowl" of Banks is eclipsed by the Internet's more flexible management and more generous pay packages in front of the knowledge workers. The double seduction of material condition and self-worth makes the employee's
Development of science and technology promote the industry transition to digital Banks, but in the process of transformation, didn't fully understand the employee's occupation planning and personal willingness, cause the deviation between actual and inner expectations of employees, thus reducing the degree of loyalty to organization. (Figure 2)

3) Single salary structure, highlight performance appraisal malpractice

At present, the salary structure of the bank staff is changing: the proportion of the basic salary is declining, and the proportion of the performance salary is rising. As China's economy has entered a "new normal", the net profit of the banking industry decreased year by year; at the same time, influenced by the reduced deposit and increased rate of nonperforming bank profits, operating pressure increasing, staff

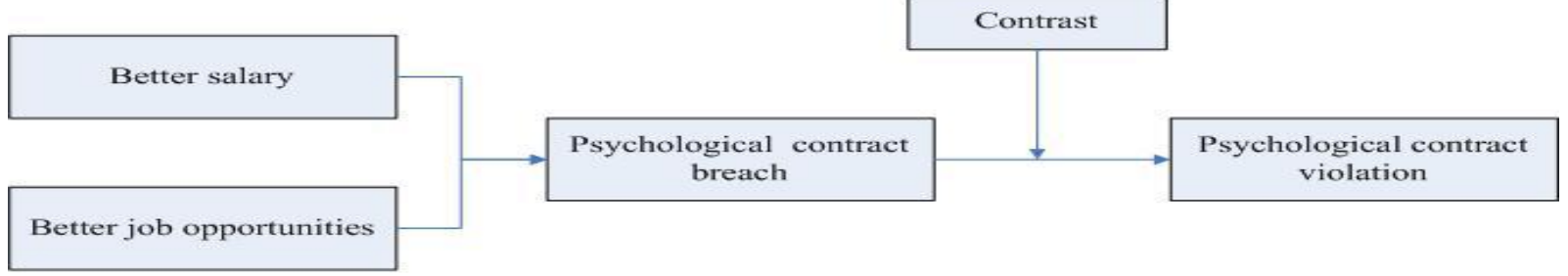

Fig. 1. The impact of the emerging financial forms for the influence of psychological contract.

loyalty declined. (Figure 1)

2) The impact of the development of science and technology

The impact and change of the financial intelligence and technology on the personal business of banks should not be underestimated. Banks have an index called departure rate, namely banking business via mobile devices, such as electronic self-service, intelligent terminal leave the counter to handle in proportion to processing at the counter. At the moment, this proportion is rising rapidly, the number of online transactions is growing at a rapid rate, while the number of clerks in traditional outlets is shrinking. The cabinet business rate is high, counter business is significantly reduced, there is bound to appear the phenomenon of the teller supply exceeds demand. The banking association data show that as of the end of 2016, ICBC teller reduced by 14090 people, ABC teller reduced 10843 people, CCB reduced 30007 people, BOC did not disclose. The increase in the utilization of electronic channels makes many employees have to adjust their posts, and in the consideration of their own career development, they have to change the job, then appear the phenomenon of "departure tide". pay cut can hardly be avoided.

From the perspective of the salary system, the salary structure of the commercial banks in our country is relatively simple, and the long-term incentive mechanism is relatively deficient, which is not conducive to stimulating the enthusiasm of employees, and it is difficult to encourage the long-term service of talents. In the state-owned commercial bank, salary is always linked to seniority, qualifications and other factors, resulting in many highly educated and knowledgeable employees' working enthusiasm is not high, unable to realize their value, this is not conducive to the bank's development. In addition, the welfare system is highly rigid, wages, bonuses and benefits are related to staff's title, and are irrelevant to labor's contribution; the incentive system largely dampened the enthusiasm and creativity of employees and enhance the flow the employees.

At present, in the performance evaluation system of the SOCB, the performance appraisal is only concerned with the financial indicators, and emphasizes the influence of the internal financial behavior on the performance of the bank, ignore the consideration of all factors. The evaluation index is unified, the appraisal form is inflexible. In actual work,

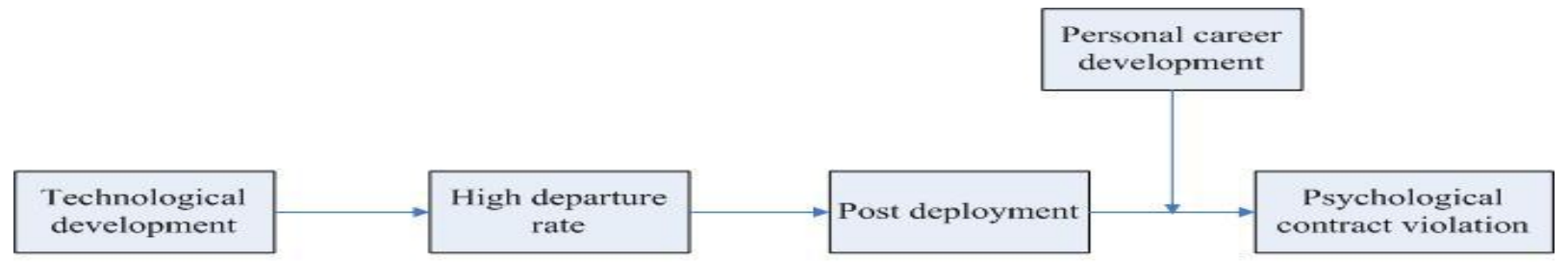

Fig. 2. The development of science and technology to the influence of psychological contract. 
because the evaluation index heavy result light process, the lack of communication between the upper and lower levels in the assessment process, their problems are not solved in time, the assessment results cannot get timely feedback, eventually leading employees only see the immediate benefits, while ignoring the bank's long-term development. This is not only hard to improve worker's working ability, but also dampened the enthusiasm and sense of belonging of employees, the employee psychological contract has breached. (Figure 3)

\section{4) The limitations of personal career development}

The administrative directive management of the SOCB is

\section{Summary}

By the impact of emerging financial industry, science and technology development, single compensation structure, obvious performance appraisal malpractice, the limitation of personal occupation, employee's psychological contract has affected constantly; through its own perception, when our expectations and the actual situation have deviant, the staff through multiple comparison, redefining the psychological contract with the organization, in the process of comparison, employees pay more attention to personal interests, ignore the organization's long-term interests, then form psychological

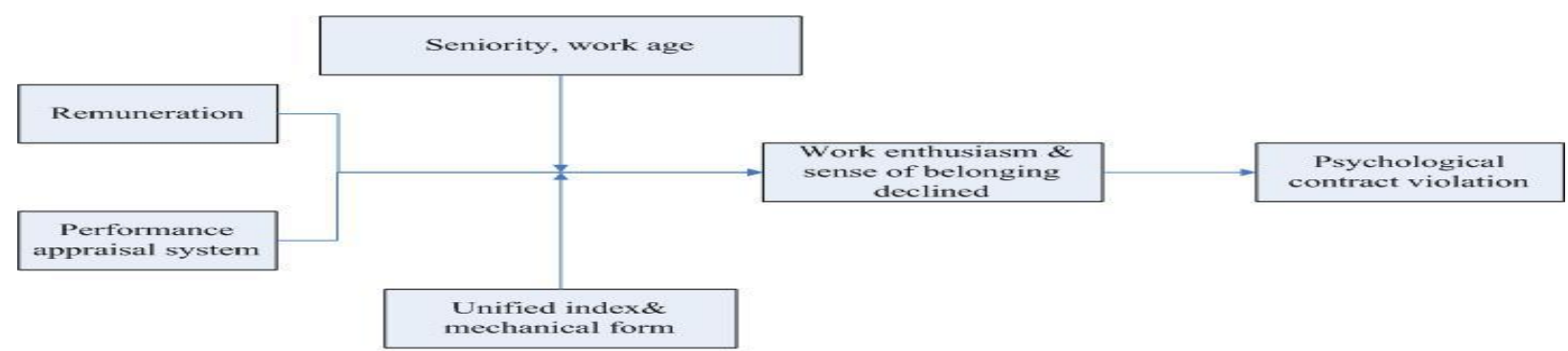

Fig. 3. Compensation and performance appraisal system for the influence of psychological contract.

a restriction on the independence, autonomy and creativity of the knowledge workers. Knowledge workers pay attention to personal development and self-realization and so on. But in Chinese management system of SOCB, most of the new employees entering the bank allocated to the grassroots, start from the teller, not to do the corresponding employee occupation career planning, to the knowledge bank staff training also not enough. For lifelong occupation planning considerations, they had to find another way.

Single promotion channel is one of the important reasons for the loss of knowledge workers in the SOCB. The interference of various factors such as seniority, administrative appointment and interpersonal relations, makes many excellent employees' career development and promotion path more difficult. The limitation of personal career development has greatly affected the enthusiasm of knowledge workers, which is not conducive to the enhancement of organizational cohesion. (Figure 4) contract violation. (Figure 5)

\section{MAINTENANCE OF KNOWLEDGE WORKERS' LOYALTY IN SOCB}

\section{A. Adjust the compensation and adjust the performance appraisal mechanism}

Taking market-based compensation, market-oriented, and establishing a compensation distribution mechanism that matches the development of the bank; more pay for more work, enhance the compensation of the salary level; combined with the specific business lines and positions, optimize the compensation system, enhance the salary efficiency. Rich the compensation's content that combines short-term incentives with long-term incentives to increase the loyalty of bank knowledge workers.

Establish a standardized performance evaluation system, prevent unfair assessment from the mechanism. To strengthen the communication between the upper and lower levels, listen

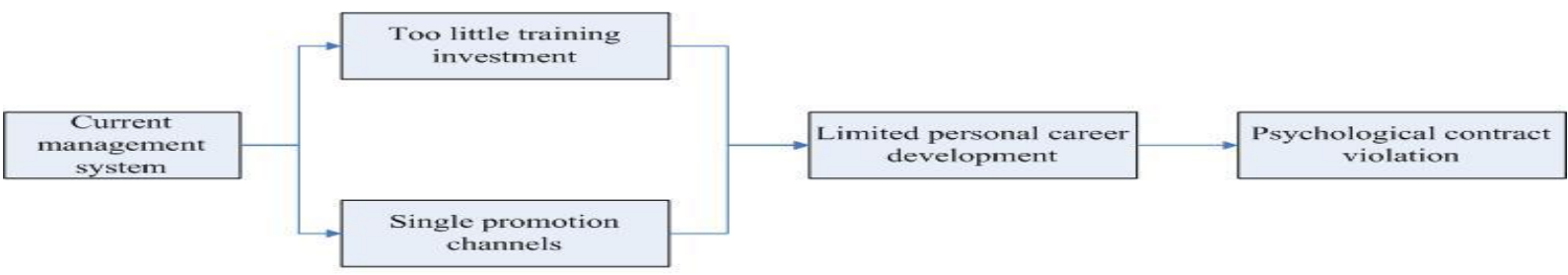

Fig. 4. Limitations of personal career development to the influence of psychological contract.

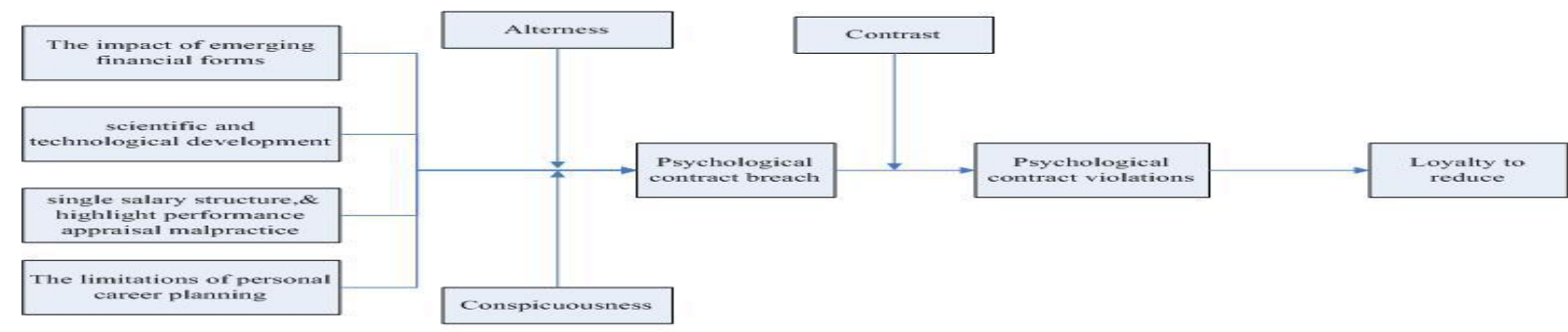

Fig. 5. Development process of staff loyalty's decline. 
to the staff's view, summed up the assessment indicators related with the contents of the work, so as to break through the traditional performance appraisal methods, translate into a comprehensive index evaluation method with clear index.

Connect the salary system with performance appraisal mechanisms closely, and then evaluate employee's work from two sides: "performance" and "efficiency". At the same time, pay attention to the material and spiritual incentive combination, which can arouse the enthusiasm of the staff, but also can ensure the fairness of compensation, and ultimately improve employee loyalty.

\section{B. Establish a good personnel management mechanism}

Pay attention to the infiltration of organizational culture, strengthen the construction of organizational culture. The organization should strengthen the staff emotional investment, consciously cultivate the employee's loyalty to the organization, adhere to the "employees first", constantly optimize the human resources management system, in order to improve employee loyalty.

Establish a good personnel management mechanism. The knowledge staff as an important resource of organization's development, organization should focus on employees' personal development needs, pay attention to the satisfaction of personal value realization, and provides better opportunities for good employees. Establish scientific talent selection and evaluation system, put an end to the "official standard" ideas, different departments and positions using different methods of selection and evaluation, according to the results of staff appraisal to make the right choice.

\section{Improve personal career development plan}

To improve the professional development channel of knowledge workers and provide diversified growth paths, such as optimize the post system, smooth career development channels; according to the difference of employee's work, We will establish a sound talent promotion channel, and select and use personnel in multiple channels, and push forward business management, professional and technical skills and operating three team consists of construction.

Improve employee training system. Organization should increase the investment of staff training, combined with the personal characteristics to organize the training, training will be linked to employees' personal growth, Help employees plan the development goals ,so that employees will be aware of the organization's concerns about personal growth and development, meanwhile, Employees appreciate the performance of the organization's commitment.

\section{CONCLUSION}

SOCB in China should be fully aware of the importance of employee loyalty to organization's development. In order to improve employee loyalty, organization should satisfy the staff's inner expectations, when the employees' perception of inner expectations deviated, organization should take action positively, within the scope of the bank regulation, by improving the compensation system, adjusting the performance appraisal mechanism, establishing a good personnel management mechanism, improving employees' personal career development planning to improve employee loyalty, thus to stabilize the normal development of the organization.

\section{ACKNOWLEDGMENT}

Firstly, I would like to extend my sincere gratitude to my tutor, Associate Professor Yang Ying, for her instructive advice and useful suggestions on my paper. I am deeply grateful for her help in the completion of this paper. Without her consistent and illuminating instruction, I can't make it successfully. Secondly, I would like to thank deeply all the other teachers and classmates in Management Studies for their direct and indirect guidance and help to me.

\section{REFERENCES}

[1] Peter Drucker, "Management Challenges for the 21st Century," Shanghai: Shanghai Translation Publishing House, 1999

[2] X. Zhao, "The mechanism and influencing factors of customer psychological contract violation," Shenyang: Northeastern University, 2012.

[3] J. Zhang, "Study on the incentive system of knowledge workers in state owned commercial banks based on psychological contract," Shandong: Ocean University of China, 2013.

[4] X.X. Zhang, and S.S. Zhang, "Analysis on how to improve the loyalty of knowledge workers," Modern economic information, 2017, pp.56-58. 